\title{
S.K.Runcorn
}

Institute of Lunar \& Planetary Sciences, School of Physics, The University, Newcastle upon Tyne, NEl 7RU, UK.

It was not generally anticipated by lunar scientists that the Moon rocks would prove to possess a natural remanent magnetization because the absence of a present field had already been demonstrated and it was almost universally believed that the Moon did not possess an iron core in which such a field could be generated. Consequently the initial investigation of Apollo 11 rocks was directed towards the use of rock magnetic studies as an adjunct to petrological examination. One of the most notable findings of the Apollo programme was the demonstration of the existence of a natural remanent magnetization (NRM) in Apollo 11 lavas and breccias. Experiments on the stability of the NRM enabled it to be concluded that the rocks were already magnetized when they were on the Moon. This conclusion was soon corroborated by the discovery of the existence of a steady magnetic field at the Apollo 12 site of the magnitude expected from the intensity of the NRM of about $36 \gamma$ (in addition to the field fluctuating solar wind. It was reasoned from this early work that the natural remanent magnetization had been acquired at the time of origin of the rocks or at least in their early history and a case was made out that this was a thermoremanent magnetization acquired as the lava flows cooled from magma flowing into the mare basin and as the high grade breccias cooled after the impacts. The origin of the natural remanent magnetization of the low grade breccias is more problematic and the role of otherkinds of remanent magnetization processes has been investigated, particularly the effect of shock.

In the early papers, arguments were presented that the natural remanent magnetization was acquired from a lunar field of internal origin, but the alternatives of external sources such as the Earth's field were considered although on the whole were thought to be less satisfactory. The mascons, local (of the order of $10 \mathrm{~km}$ ) regions of field of the order of $10 \gamma$ in strength, inferred from the deflection of the solar wind and the magnetic anomalies observed from the subsatellites have been explained in terms of a general magnetization of the lunar crust, the emergence of the lines of force being ascribed to edges, especially those of the large craters. The new nethod of 
plotting the magnetic field of the Moon at the surface by the observations of reflected electrons has given some support to this, for the horizontal scale of these anomalies are much less than those observed from the height of the sub-satellite. Similarly the exceedingly low upper limit now set to the present lunar dipole moment $0.05 \gamma$ at the surface has been interpreted by postulating that the field which magnetized the outer part of the Moon was of internal rather than external origin.

Comparatively few palaeointensity measurements on the Apollo samples have yet been made and values found for the ancient lunar field range from $1,000 \gamma$ to 1 Gauss but it has latterly been suggested that these, at first sight apparently conflicting results, can be reconciled if the palaeointensity of the lunar field diminished exponentially with time by nearly two orders of magnitude from $4.010^{9}$ yr to $3.210^{9} \mathrm{yr}$.

All these conclusions have been subject to critical comment but a few alternative suggestions concerning the origin of the remanent magnetization and also of the origin of the magnetizing field have been made and have been tested as far as possible with the limited amount of observational material. The physical basis of the palaeointensity determinations has also been under study and in the few cases where the alternative Thellier/Thellier and a.r.m. methods have been compared there has been reasonable agreement.

The conclusions arrived at above are still tentative, but if they are correct very important conclusions concerning the early history of the Moon follow. The most straightforward interpretation is that the Moon possessed an iron (i.e. electrically conducting)core from its earliest history at least from $410^{9} \mathrm{yr}$, that the heat sources diminished rapidly. with time and other influences (e.g. rotation) driving the dynamo became less effective between 4.0 and $3.2 \mathrm{~b}, \mathrm{y}$. so that large changes in the field strength occurred. At a later unknown date the magnetic Reynolds number dropped below the critical value for the sustaining of dynamo action, or perhaps the core solidified, some time in the last $3.2 \mathrm{~b} . \mathrm{y}$. so that today the dynamo is not operating. We think that future progress will depend on a concerted effort to study further the fundamental basis of the palaeointensity and to obtain further evidence on the origin of the remanent magnetization. A vital test of the ideas which are emerging in lunar magnetism requires the gathering of more data especially from rocks of various ages to see whether a clear pattern and a self consistency emerges. The environment in which the lunar rocks originated and have since existed is very different from that in the terrestrial case so that studies of these environments, for example shock, require further study by laboratory methods. 


\section{Genera1 References}

S.K.Runcorn, D.W.Collinson, W.O'Reilly, M.H.Battey, A.Stephenson, J.M.Jones, A.J.Manson and P,W.Readman, Magnetic properties of Apollo 11 lunar samples, In Proceedings of the Apollo 11 Lunar Science Conference, vol. 3, 2369-2387, 1970.

S.K.Runcorn, D.W.Collinson, W.O'Reilly, A.Stephenson, M.H.Battey, A.J.Manson \& P.W.Readman, Magiietic properties of Apollo 12 lunar samples, Proc.Roy.Soc.Lond.A.325, 157-174, 1971.

S.K.Runcorn, D.W.Collinson, A.Stephenson and A.J.Manson, Magnetic properties of Apollo 14 rocks and fines, Proc. 3rd Lunar Sci.Conf., Geochimica et Cosmochimica Acta, Supp1. 3, 3, 2343-2361, 1972.

S.K.Runcorn, D.W.Collinson and A.Stephenson, Magnetic properties of Apollo 15 and 16 rocks, Proc. 4th Lunar Sci.Conf., Geochim, et Cosmochim.Acta, Supp1. 4, 3, 2963-2976, 1973.

S.K.Runcorn, On the origin of mascons and moonquakes, Proc. 5th Lunar Sci.Conf., Geochimica et Cosmochimica Acta, Supp1. 5, 3, 3115-3126, 1974.

S.K.Runcorn, A.Stephenson, D.W.Collinson, Lunar magnetic field palaeointensity determinations on Apollo 11, 16 and 17 rocks. Proc. 5 th Lunar Sci.Conf., Geochim. et Cosmochim.Acta, Suppl. 5, 3 , 2859-2871, 1974.

S.K.Runcorn, A.Stephenson and D.W.Collinson. On changes in the intensity of the ancient lunar magnetic field. Proc. 6th Lunar Sci. Conf., Geochimica et Cosmochimica Acta, Supp1. 6, 3049-3062, 1975.

S.K.Runcorn, Solid state convection and the mechanics of the Moon, Proc.Lunar Sci.Conf. 6th., Geochimica et Cosmochimica Acta, Suppl. 6, 2943-2953, 1975.

S.K.Runcorn, Inferences concerning the early thermal history of the Moon. Proc. 7 th Lunar Sci.Conf., Geochim. et Cosmochim.Acta, Supp1. 7, $3221-3228$, 1976.

S.K.Runcorn, A.Stephenson and D.W.Collinson, On the intensity of the ancient lunar magnetic field, Proc. 7 th Lunar Sci.Conf., Geochimica et Cosmochimica Acta, Supp1. 7, 3373-3382, 1976. 